\title{
Intervention study of Snyder's hope theory on the stigma of stroke in young and middle-aged patients: a randomised trial
}

\author{
Chunxia Ge ${ }^{1}$, Hua Zhang ${ }^{2}$, Guoyun Zhu $^{2}$, Aiping $\mathrm{Cao}^{1}$, Jianping Zhang ${ }^{3}$ \\ ${ }^{1}$ Department of Neurology, Affiliated Haian Hospital of Nantong University, Nantong, China; ${ }^{2}$ Department of Neurology, Affiliated Hospital of \\ Nantong University, Nantong, China; ${ }^{3}$ Department of Rehabilitation Medicine, Affiliated Haian Hospital of Nantong University, Nantong, China \\ Contributions: (I) Conception and design: C Ge, H Zhang; (II) Administrative support: H Zhang; (III) Provision of study materials or patients: C Ge, \\ G Zhu, A Cao; (IV) Collection and assembly of data: C Ge, G Zhu, A Cao, J Zhang; (V) Data analysis and interpretation: C Ge, A Cao, J Zhang; (VI) \\ Manuscript writing: All authors; (VII) Final approval of manuscript: All authors. \\ Correspondence to: Hua Zhang. Department of Neurology, Affiliated Hospital of Nantong University, Nantong 226001, China. Email: Zgy-xx@163.com.
}

Background: Stigma refers to the sense of discrimination that society has towards a certain group of
people, and this part of the group will also have a sense of shame due to their own negative circumstance.
Young and middle-aged stroke patients need long-term effective support from their families and society,
which can easily produce shame, and have a negative impact on disease treatment.
Methods: A total of 94 young and middle-aged stroke patients admitted to our hospital from November
2018 to November 2020 were selected and randomly allocated to 2 groups, with 47 cases in each group.
The control group received routine intervention, and the observation group received SHT intervention.
The stigma, hope level, compliance with functional exercise, National Institute of Health Stroke Scale
(NIHSS) score and changes in activities of daily living were compared between the 2 groups before and after
intervention.

Results: The total scores of social interaction, treatment, ability, and stigma of the observation group were lower than those of the control group after 1 month of intervention $(\mathrm{P}<0.05)$. The observation group's positive attitude towards reality and the future, taking positive actions, maintaining close relationships with others, and hope levels after 1 month of intervention were all higher than the control group $(\mathrm{P}<0.05)$. The functional exercise compliance of the observation group was higher than that of the control group after 1 month of intervention $(\mathrm{P}<0.05)$. The Barthel index score of the observation group was higher than that of the control group after 1 month of intervention, and the NIHSS score was lower than that of the control group $(\mathrm{P}<0.05)$.

Conclusions: The application of SHT to young and middle-aged stroke patients can reduce stigma, improve hope level and compliance with functional exercise, improve neurological function, and enhance the ability for daily living.

Trial Registration: Chinese Clinical Trial Registry ChiCTR2100045926.

Keywords: Snyder's hope theory (SHT); young and middle-aged; stroke; stigma; ability of daily living

Submitted Jan 21, 2021. Accepted for publication Apr 23, 2021.

doi: $10.21037 /$ apm-21-441

View this article at: http://dx.doi.org/10.21037/apm-21-441

\section{Introduction}

The incidence rate of stroke is increasing among young and middle-aged people. At present, there are 70 million stroke patients in China. With the advance of stroke onset age, more than $50 \%$ of stroke patients are 18-60 years old (1).
According to who's classification criteria the age of young and middle-aged people is $18-60$ years old (2). Therefore, young and middle-aged stroke refers to the stroke in adults aged 18-60.

Stigma refers to the sense of discrimination that society 
has towards a certain group of people, and this group will also carry a sense of shame due to their own negative circumstances $(3,4)$. Sjogren investigated 51 first-episode stroke patients' participation in recreational activities and satisfaction within one year, and used five item stigma scale to investigate. The results showed that $50 \%$ of the patients had stigma within one year after stroke (5). Young and middle-aged stroke patients need long-term effective support from their families and society, which can easily produce shame, have a greater impact on their psychology, significantly reduce their quality of life, and have a negative impact on disease treatment (6). At present, domestic research on stigma has mainly involved patients with intestinal stoma (7), and there have been few studies on stigma of stroke in young and middleaged people. Snyder's hope theory (SHT) analyzes hope from 3 aspects: establishing goals, path beliefs, and willing beliefs. Establishing goals is the core of SHT, path beliefs are the bridge between the current and future situation of individuals through goals, and willingness beliefs are the driving force to help individuals advance toward their goals $(8,9)$. This study applied SHT to young and middleaged stroke patients, and explored the influence of SHT on stigma, hope level, compliance with functional exercise, National Institute of Health Stroke Scale (NIHSS) score, and changes in activities of daily living. We present the following article in accordance with the CONSORT reporting checklist (available at http://dx.doi.org/10.21037/ apm-21-441).

\section{Methods}

\section{Patient selection}

A total of 94 young and middle-aged stroke patients admitted to our hospital from November 2018 to November 2020 were selected and randomly allocated to 2 groups, with 47 cases in each group. The inclusion criteria were as follows: (I) meet the diagnostic criteria for stroke; (II) aged over 18 years old but under 60 years old; (III) clear consciousness; (IV) first onset; (V) patients and their families signed informed consent. The exclusion criteria were as follows: (I) comorbidity of severe hematological diseases; (II) combined with severe heart, liver, kidney, lung, and other organ dysfunctions; (III) combined with severe metabolic diseases; (IV) combined with severe endocrine diseases; (V) combined with malignant tumors; (VI) combined with severe cognitive dysfunction; (VII) critical illness; (VIII) mental illness; (IX) incomplete clinical data. The study was approved by the Ethics Committee of Affiliated Haian Hospital of Nantong University ([2018] KY049) and conducted in accordance with the Declaration of Helsinki (as revised in 2013). All subjects provided informed consent.

\section{Interventions}

The control group was administered with routine interventions, and participants were given routine treatment of diseases and complications. Rehabilitation training was carried out after their condition was stable for $48 \mathrm{~h}$, including passive movement of the affected limb, correct placement of the good limb, exercise on the bed and bedside, sitting and standing strength training, walking exercise, and so on. The intervention staff adjusted the intervention plan in real time according to the recovery of each participant.

The observation group received SHT intervention on the basis of the control group. The SHT intervention was performed by the following steps: (I) establishment of an SHT intervention team. Team members included the head nurse, specialist nurses, psychological counselors, and rehabilitation therapists. All members had more than 5 years of clinical work experience. All members received intensive training every week for 1 month. The training content included SHT related content, clinical application methods, correct methods of communication with patients. and related knowledge of rehabilitation training. Assessments were carried out after the training, and the intervention was implemented after all members had passed the assessment. (II) Evaluation. Intervention staff counted and recorded the general information and psychological status of participants, and established health files for each participant. (III) Specific intervention measures: (i) Health education. Intervention staff explained in detail the meaning of SHT and its relationship with disease and health to participants and their families, and fully activated participant enthusiasm for disease treatment. (ii) Establish goals. According to the established health records, staff spoke with participants and family members to formulate general goals, simultaneously divided them into feasible small goals, and then trained patients to cultivate a positive hope state. When formulating goals, it should be noted that from simple to complex, daily, weekly, and monthly were correspondingly targeted plans. After completing each goal plan, the intervention staff gave full encouragement and moved on to the next goal. If the 
goal was not completed, the reasons were discussed with the participant and their family members, solutions were formulated, and the next stage was entered after completing the goal. (iii) Build path beliefs. According to the current work, family, and learning status of each participant, help was given to find the right way to connect with their future goals. Participants were helped to plan the goal path, correctly recognize their self-worth, and understand the importance of self-management for body recovery. (iv) Build willingness and belief. Intervention staff distributed stroke rehabilitation instruction manuals to participants and their families, and regularly distributed knowledge about stroke rehabilitation exercises to them through the WeChat platform. Psychological counselors provided reasonable mood regulating therapy to help participants process the emotional shock period smoothly, even if the participant appeared to have accepted the objective facts of having suffered a stroke, adjusted their own emotions, and recognized the future ramifications. (v) Rehabilitation guidance. Intervention staff implemented early inbed rehabilitation care after the participant's vital signs were stable and the neurological symptoms had stopped progressing, mainly including both handshaking and proper positioning of limbs. Daily living ability exercises included dressing and disrobing training, eating exercises, and toilet management. The exercises were undertaken 1 time/ d, for 30-45 min/time. Language rehabilitation training initially started with loud voice development training, and then conduction of monosyllable-word-phrase-normal communication. During this period, gestures, words, and so on could be used for descriptive communication. Intervention staff enthusiastically encouraged participants during training to foster their confidence in rehabilitation training.

\section{Evaluation indexes}

\section{Stigma}

The stigma assessment scale was used to evaluate the stigma before the intervention and 1 month after the intervention. There were 3 dimensions and 32 items, each item was scored 0-3, and the total score was 0-96. The higher the score, the higher the stigma (10).

\section{Hope level}

The Herth Hope Scale was used to evaluate the level of hope before, and 1 month after, the intervention. There are 3 dimensions, 12 items, each item is $1-4$ points, and the total score is $12-48$ points. The higher the score, the higher the level of hope (11).

\section{Compliance with functional exercise}

The compliance questionnaire was used to evaluate the compliance of functional exercise before and one month after the intervention. The scale includes the time and frequency to complete functional exercises in accordance with the doctor's instructions. The total score is $0-3$ points, 0 is poor compliance, $1-2$ is moderate compliance, and 3 is good compliance (12).

\section{NIHSS score and changes in activities of daily living}

The NIHSS was used to evaluate the degree of neurological deficit before intervention and then 1 month after. The total score is $0-42$. The higher the score, the more serious the neurological deficit (13). The Barthel index scale was used to evaluate the ability of daily living before the intervention and one month after the intervention, with a total score of $0-100$. The higher the score, the stronger the ability of daily living (14).

\section{Statistical analyses}

The statistical analysis in this study was performed using SPSS 20.0 (SPSS Inc., Chicago, IL, USA). The stigma, hope level, NIHSS score, and changes in activities of daily living were expressed as mean \pm standard deviation and compared using 2-tailed $t$-tests. Compliance with functional exercise was expressed by rates and percentages, and compared using the chi-squared $\left(\chi^{2}\right)$ test or rank-sum test. A $\mathrm{P}$ value $<0.05$ was considered statistically significant.

\section{Results}

\section{General information}

This study included 94 young and middle-aged stroke patients. The control group included 31 males and 16 females; aged 20-58 years old, with an average age of $(49.81 \pm 5.27)$ years; education level: 16 cases of junior high school and below, 19 cases of high school or technical secondary school, 12 cases of junior college or above; Family income: 4 cases were less than 4,000 yuan, 22 cases were $4,000-8,000$ yuan; 21 cases were more than 8,000 yuan. The observation group included 29 males and 18 females; aged 22-59 years old, with an average age of $(49.55 \pm 5.41)$ years; education level: 14 cases of junior high school and below, 


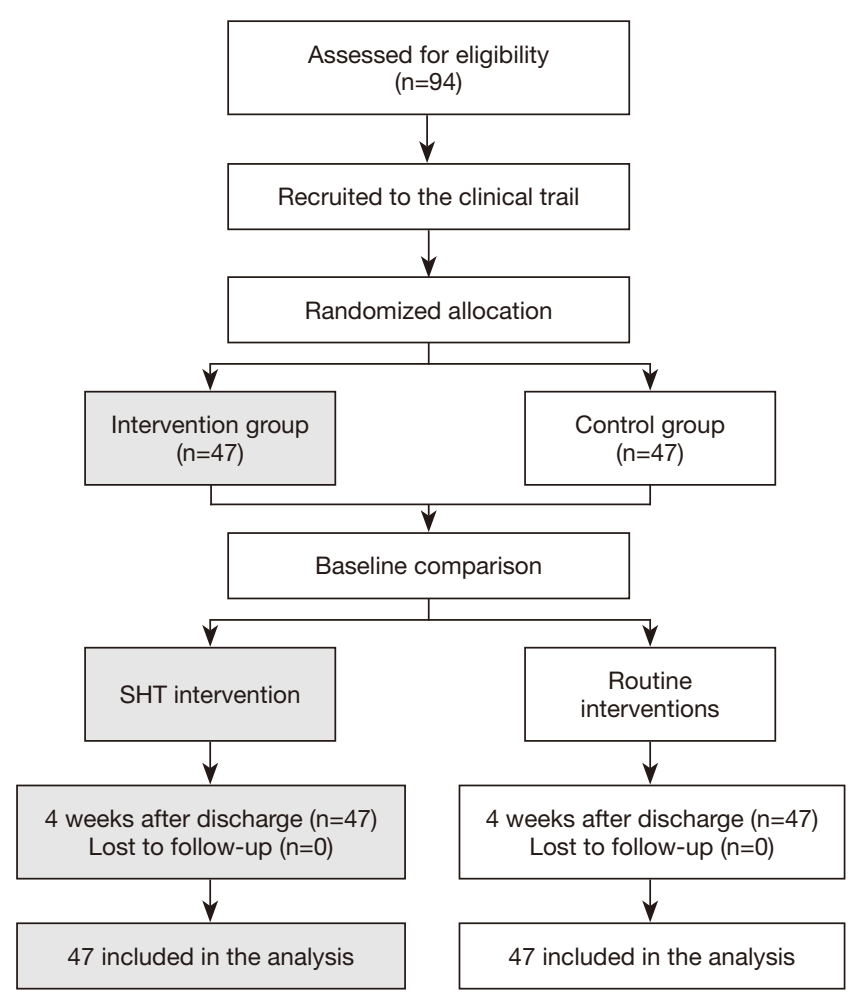

Figure 1 Study profile.
20 cases of high school or technical secondary school, and 13 cases of junior college or above; Family income: 4 cases were less than 4,000 yuan, 24 cases were $4,000-8,000$ yuan; 19 cases were more than 8,000 yuan. There were no statistically significant differences between the 2 groups of patients in general data such as gender, age, education level, and family income $(\mathrm{P}>0.05)$ (Figure 1, Table 1).

\section{Stigma}

Before the intervention, there were no statistical differences in the total scores of social interaction, treatment, ability, and stigma of the 2 groups $(t=0.121,0.289,0.199$, $0.132 ; \mathrm{P}=0.904,0.773,0.842,0.896)$. A month after the intervention, the total scores of social interaction, treatment, ability, and stigma of the observation group were lower than those of the control group ( $t=5.490,7.567,7.346$, 8.281; $\mathrm{P}=0.000,0.000,0.000,0.000$ ) (Table 2).

\section{Hope level}

Before the intervention, there were no statistical differences in participant's positive attitude towards reality and

Table 1 Comparison of general information of the 2 groups (n, \%)

\begin{tabular}{|c|c|c|c|c|}
\hline Variables & Control group $(n=47)$ & Observation group $(n=47)$ & Statistic value & $P$ value \\
\hline Age $(\bar{x} \pm s$, years $)$ & $49.81 \pm 5.27$ & $49.55 \pm 5.41$ & $\mathrm{~T}=0.236$ & 0.814 \\
\hline Gender & & & $\chi^{2}=0.184$ & 0.668 \\
\hline Male & $31(65.96)$ & $29(61.70)$ & & \\
\hline Female & $16(34.04)$ & $18(38.30)$ & & \\
\hline Education level & & & $\chi^{2}=0.199$ & 0.905 \\
\hline Junior high school and below & $16(34.04)$ & $14(29.79)$ & & \\
\hline High school or technical secondary school & $19(40.43)$ & $20(42.55)$ & & \\
\hline Junior college or above & $12(25.53)$ & $13(27.66)$ & & \\
\hline Family income (yuan) & & & $\chi^{2}=0.187$ & 0.911 \\
\hline$<4,000$ & $4(8.51)$ & $4(8.51)$ & & \\
\hline $4,000-8,000$ & $22(46.81)$ & $24(51.06)$ & & \\
\hline$>8,000$ & $21(44.68)$ & $19(40.43)$ & & \\
\hline
\end{tabular}


Table 2 Comparison of stigma before and after intervention between the 2 groups $(\bar{x} \pm \mathrm{s}$, points)

\begin{tabular}{|c|c|c|c|c|c|}
\hline Time & Group & Social interaction & Treatment & Ability & The total scores of stigma \\
\hline \multirow{3}{*}{$\begin{array}{l}\text { Before the } \\
\text { intervention }\end{array}$} & Observation group $(n=47)$ & $25.89 \pm 6.07$ & $16.72 \pm 3.58$ & $12.64 \pm 2.09$ & $56.01 \pm 9.85$ \\
\hline & $t$ value & 0.121 & 0.289 & 0.199 & 0.132 \\
\hline & $P$ value & 0.904 & 0.773 & 0.842 & 0.896 \\
\hline \multirow{3}{*}{$\begin{array}{l}1 \text { month after the } \\
\text { intervention }\end{array}$} & Observation group $(n=47)$ & $17.25 \pm 5.13$ & $11.27 \pm 2.95$ & $8.91 \pm 1.84$ & $37.74 \pm 7.29$ \\
\hline & $t$ value & 5.490 & 7.567 & 7.346 & 8.281 \\
\hline & $P$ value & 0.000 & 0.000 & 0.000 & 0.000 \\
\hline
\end{tabular}

Table 3 Comparison of hope levels between the 2 groups before and after intervention $(\bar{x} \pm \mathrm{s}$, points)

\begin{tabular}{|c|c|c|c|c|c|}
\hline Time & Group & $\begin{array}{l}\text { Positive attitude towards } \\
\text { reality and the future }\end{array}$ & $\begin{array}{l}\text { Taking positive } \\
\text { actions }\end{array}$ & $\begin{array}{l}\text { Maintaining close } \\
\text { relationships with others }\end{array}$ & $\begin{array}{c}\text { Total score of } \\
\text { hope levels }\end{array}$ \\
\hline \multirow{3}{*}{$\begin{array}{l}\text { Before the } \\
\text { intervention }\end{array}$} & Control group $(n=47)$ & $9.03 \pm 1.02$ & $9.08 \pm 1.09$ & $11.15 \pm 1.16$ & $31.07 \pm 1.98$ \\
\hline & Observation group $(n=47)$ & $9.11 \pm 1.14$ & $9.01 \pm 1.05$ & $11.27 \pm 1.21$ & $31.25 \pm 2.04$ \\
\hline & $t$ value & 0.359 & 0.317 & 0.491 & 0.434 \\
\hline \multirow{4}{*}{$\begin{array}{l}1 \text { month after the } \\
\text { intervention }\end{array}$} & Control group $(n=47)$ & $10.25 \pm 1.24$ & $10.13 \pm 1.15$ & $12.03 \pm 1.31$ & $33.06 \pm 3.47$ \\
\hline & Observation group $(n=47)$ & $12.84 \pm 1.31$ & $13.76 \pm 1.29$ & $14.94 \pm 1.27$ & $41.75 \pm 3.87$ \\
\hline & $t$ value & 9.844 & 14.400 & 10.934 & 11.462 \\
\hline & $P$ value & 0.000 & 0.000 & 0.000 & 0.000 \\
\hline
\end{tabular}

the future, taking positive actions, maintaining close relationships with others, and hope levels of the 2 groups $(t=0.359,0.317,0.491,0.434 ; \mathrm{P}=0.721,0.752,0.625,0.665)$. A month after the intervention, the observation group's positive attitudes towards reality and the future, taking positive actions, maintaining close relationships with others, and hope levels were all higher than those of the control group $(t=9.844,14.400,10.934,11.462 ; \mathrm{P}=0.000), 0.000$, $0.000,0.000)$ (Table 3).

\section{Compliance with functional exercise}

Before the intervention, there was no statistical difference in the functional exercise compliance of the 2 groups $\left(\chi^{2}=0.173\right.$, $\mathrm{P}=0.917)$. A month after the intervention, the compliance of the observation group was higher than that of the control group $\left(\chi^{2}=8.825, \mathrm{P}=0.012\right)$ (Table 4).

\section{NIHSS score and changes in activities of daily living}

Before the intervention, there were no statistical differences between the Barthel index scores and NIHSS scores of the 2 groups $(t=0.256,0.153 ; \mathrm{P}=0.799,0.879)$. A month after the intervention, the Barthel index score of the observation group was higher than that of the control group, and the NIHSS score was lower than that of the control group $(t=6.617,11.476 ; \mathrm{P}=0.000,0.000)$ (Table 5).

\section{Discussion}

Young and middle-aged stroke patients are prone to stigma, and concurrently, such patients have low levels of self-esteem and social support (15). The younger the young and middle-aged stroke patients, the lower the monthly income, the more severe the stigma; and the more 
Table 4 Comparison of compliance with functional exercise between the 2 groups before and after intervention (n, \%)

\begin{tabular}{|c|c|c|c|c|}
\hline Time & Group & Good compliance & Moderate compliance & Poor compliance \\
\hline \multirow{3}{*}{ Before the intervention } & Observation group $(n=47)$ & $10(21.28)$ & $12(25.53)$ & 25 (53.19) \\
\hline & $\chi^{2}$ value & & 0.173 & \\
\hline & $P$ value & & 0.917 & \\
\hline \multirow{3}{*}{1 month after the intervention } & Observation group $(n=47)$ & $30(63.83)$ & $15(31.91)$ & $2(4.26)$ \\
\hline & $\chi^{2}$ value & & 8.825 & \\
\hline & $P$ value & & 0.012 & \\
\hline
\end{tabular}

Table 5 Comparison of NIHSS score and changes in activities of daily living between the 2 groups before and after intervention $(x \pm \mathrm{s}$, points)

\begin{tabular}{lccc}
\hline Time & Group & Barthel index score & NIHSS \\
\hline Before the intervention & Control group $(\mathrm{n}=47)$ & $41.28 \pm 5.65$ & $19.37 \pm 4.22$ \\
& Observation group $(\mathrm{n}=47)$ & $41.58 \pm 5.73$ & $19.51 \pm 4.63$ \\
& $t$ value & 0.256 & 0.153 \\
1 month after the intervention & P value & 0.799 & 0.879 \\
& Control group $(\mathrm{n}=47)$ & $46.84 \pm 6.27$ & $16.28 \pm 3.05$ \\
& Observation group $(\mathrm{n}=47)$ & $56.04 \pm 7.18$ & $10.22 \pm 1.95$ \\
& $t$ value & 6.617 & 11.476 \\
\hline
\end{tabular}

NIHSS, National Institute of Health Stroke Scale.

harmonious family and marital status, the higher the degree of social support, the lighter the stigma $(16,17)$. Stigma will cause patients to delay medical treatment, and treatment compliance will decrease significantly. Clinically, effective social support should be given to such patients, so that they can gain confidence in the recovery of the body and minimize their stigma. In this study, significant results were achieved by implementing SHT intervention in young and middle-aged stroke patients.

The results of this study showed that the total scores of social interaction, treatment, ability, and stigma of the observation group were lower than those of the control group after 1 month of intervention $(\mathrm{P}<0.05)$. This showed that the implementation of SHT intervention for young and middle-aged stroke patients could effectively improve their stigma. The main reasons for these results were that SHT requires intervention staff to assist patients and their families to collaboratively clarify goals, establish the correct avenue between current and future goals, and help patients stabilize the period of excessive emotional shock through psychological and social support, and post-treatment rehabilitation exercises (18). Intervention staff also need to help patients establish correct cognition, so that they can actively participate in their disease rehabilitation, and work hard to achieve the goals set, so as to re-establish a new sense of self after stroke (19).

The results of this study also revealed that the observation group's positive attitude towards reality and the future, taking positive actions, maintaining close relationships with others, and hope levels after 1 month of intervention were all higher than the control group $(\mathrm{P}<0.05)$. It showed that SHT intervention could significantly improve the level of patient hope. The main reasons for these results were that the intervention measures used the theory of hope as the overall framework, which can improve the patients' mental outlook after illness and face the disease 
with a positive attitude. In addition, intervention personnel need to help patients establish overall goals, and further subdivide them into feasible small goals, so that patients can attain a sense of accomplishment while completing the goals, reshape their hope of recovery, and ultimately effectively improve their hope level (20).

In addition, after 1 month of intervention, the functional exercise compliance of the observation group was higher than that of the control group, the Barthel index score was higher than that of the control group, and the NIHSS score was lower than that of the control group $(\mathrm{P}<0.05)$. It showed that SHT intervention could effectively improve exercise compliance and neurological function among patients, and enhance their ability of daily living. This is mostly due to the fact that functional exercise is an important measure to restore the ability of daily living in stroke patients after treatment, and is of great significance to the recovery of their bodies. The psychological status of stroke patients, the degree of awareness of post-treatment exercise, and family social support are all factors that affect the compliance of functional exercise (21). In the SHT intervention, the intervention staff establish scientific goals, raise the level of hope, stimulate internal motivation, and transform passive intervention into active participation in disease management, thereby enhancing the compliance and effectiveness of patient exercise, promoting the recovery of nerve function, and the ability of daily living (22).

\section{Conclusions}

The application of SHT to young and middle-aged stroke patients can reduce stigma, improve hope level and compliance with functional exercise, improve neurological function, and enhance the ability of daily living.

\section{Acknowledgments}

Funding: This work was supported by Nantong Municipal Science and Technology Plan Project (MSZ19235) and Nantong Municipal Science and Technology Plan Project (MSZ18227).

\section{Footnote}

Reporting Checklist: The authors have completed the CONSORT reporting checklist. Available at http://dx.doi. org/10.21037/apm-21-441
Data Sharing Statement: Available at http://dx.doi. org/10.21037/apm-21-441

Conflicts of Interest: All authors have completed the ICMJE uniform disclosure form (available at http://dx.doi. org/10.21037/apm-21-441). The authors have no conflicts of interest to declare.

Etbical Statement: The authors are accountable for all aspects of the work in ensuring that questions related to the accuracy or integrity of any part of the work are appropriately investigated and resolved. The study was approved by the Ethics Committee of Affiliated Haian Hospital of Nantong University ([2018]KY049) and conducted in accordance with the Declaration of Helsinki (as revised in 2013). All participants provided informed consent.

Open Access Statement: This is an Open Access article distributed in accordance with the Creative Commons Attribution-NonCommercial-NoDerivs 4.0 International License (CC BY-NC-ND 4.0), which permits the noncommercial replication and distribution of the article with the strict proviso that no changes or edits are made and the original work is properly cited (including links to both the formal publication through the relevant DOI and the license). See: https://creativecommons.org/licenses/by-nc-nd/4.0/.

\section{References}

1. Takashima R, Murata W, Saeki K. Movement changes due to hemiplegia in stroke survivors: a hermeneutic phenomenological study. Disabil Rehabil 2016;38:1578-91.

2. World Health Organization. (2012). World Health Day 2012: ageing and health: toolkit for event organizers. World Health Organization.

3. Iampreechakul P, Tanpun A, Lertbusayanukul P, et al. Contralateral extensive cerebral hemorrhagic venous infarction caused by retrograde venous reflux into the opposite basal vein of Rosenthal in posttraumatic carotidcavernous fistula: A case report and literature review. Interv Neuroradiol 2018;24:546-58.

4. Fu CH, Li KS, Ning YZ, et al. Altered effective connectivity of resting state networks by acupuncture stimulation in stroke patients with left hemiplegia: A multivariate granger analysis. Medicine (Baltimore) 2017;96:e8897. 
5. Sjögren K. Leisure after stroke. Int Rehabil Med 1982;4:80-7.

6. Khoshbakht Pishkhani M, Dalvandi A, Ebadi A, et al. Factors affecting adherence to rehabilitation in Iranian stroke patients: A qualitative study. J Vasc Nurs 2019;37:264-71.

7. Ni C, Peng J, Wei Y, et al. Uncertainty of Acute Stroke Patients: A Cross-sectional Descriptive and Correlational Study. J Neurosci Nurs 2018;50:238-43.

8. Walker MF, Hoffmann TC, Brady MC, et al. Improving the development, monitoring and reporting of stroke rehabilitation research: Consensus-based core recommendations from the Stroke Recovery and Rehabilitation Roundtable. Int J Stroke 2017;12:472-9.

9. Hong I, Karmarkar A, Chan W, et al. Discharge Patterns for Ischemic and Hemorrhagic Stroke Patients Going From Acute Care Hospitals to Inpatient and Skilled Nursing Rehabilitation. Am J Phys Med Rehabil 2018;97:636-45.

10. Tanz LJ, Stuart JJ, Williams PL, et al. Preterm Delivery and Maternal Cardiovascular Disease in Young and Middle-Aged Adult Women. Circulation 2017;135:578-89.

11. Hasnain MG, Levi CR, Ryan A, et al. Can a multicomponent multidisciplinary implementation package change physicians' and nurses' perceptions and practices regarding thrombolysis for acute ischemic stroke? An exploratory analysis of a cluster-randomized trial. Implement Sci 2019;14:98.

12. Kwon HK, Lee SJ. The Effect of a Movie-Based Nursing Intervention Program on Rehabilitation Motivation and Depression in Stroke Patients. J Korean Acad Nurs 2017;47:345-56.

13. Zhiyan H, Nin L, Baoyun C, et al. Rehabilitation Nursing for Cerebral Stroke Patients within a Suitable Recovery Empty Period. Iran J Public Health 2017;46:180-5.

14. Ibeneme SC, Nwosu AO, Ibeneme GC, et al. Distribution of symptoms of post-stroke depression in relation to some

Cite this article as: Ge C, Zhang $\mathrm{H}$, Zhu G, Cao A, Zhang J. Intervention study of Snyder's hope theory on the stigma of stroke in young and middle-aged patients: a randomised trial. Ann Palliat Med 2021;10(5):5721-5728. doi: 10.21037/apm-21-441 characteristics of the vulnerable patients in socio-cultural context. Afr Health Sci 2017;17:70-8.

15. Green TL, Singh P, King-Shier K. The impact of ethnic/ racial status on access to care and outcomes after stroke: A narrative systematic review. J Vasc Nurs 2019;37:199-212.

16. Ibeneme SC, Nwosu A, Anyachukwu CC, et al. Measurement of Patients' Perceptions of the Quality of Acute Stroke Services: Development and Validation of the STROKE Perception Report. Afr Health Sci 2017;17:859-67.

17. Alexandrov AW, Brewer BB, Moore K, et al. Measurement of Patients' Perceptions of the Quality of Acute Stroke Services: Development and and Validation of the STROKE Perception Report. J Neurosci Nurs 2019;51:208-16.

18. Magwood GS, Ellis C, Nichols M, et al. Barriers and Facilitators of Stroke Recovery: Perspectives From African Americans With Stroke, Caregivers and Healthcare Professionals. J Stroke Cerebrovasc Dis 2019;28:2506-16.

19. Guo Y, Lin B, Zhang Z, et al. Cross-Cultural Adaptation and Validation of the Chinese Version of the Work-Ability Support Scale (WSS) in Young and Middle-Aged Stroke Survivors. J Occup Rehabil 2020;30:646-55.

20. Saini M, Belson S, Lahiff-Jenkins C, et al. Top 10 global educational topics in stroke: A survey by the World Stroke Organization. Int J Stroke 2019;14:843-9.

21. Wessol JL, Russell CL, Olds KE. A Pilot Randomized Controlled Trial Testing the Feasibility and Acceptability of a SystemCHANGE Intervention to Improve Medication Adherence in Older Adult Stroke Survivors. J Neurosci Nurs 2019;51:259-65.

22. Pothiban L, Srirat C. Association between stroke knowledge, stroke awareness, and preventive behaviors among older people: A cross-sectional study. Nurs Health Sci 2019;21:399-405.

(English Language Editor: J. Jones) 